\title{
Mission Critical: Thoracic Surgery Education Reform
}

\author{
W. Randolph Chitwood, Jr, MD, Thomas L. Spray, MD, Richard H. Feins, MD, and Michael J. Mack, MD
}

See related article on page 814 .

During the last 50 years, education of cardiothoracic surgical residents and practicing surgeons has proven effective and has met the needs of our patients. However, today significantly fewer medical students and surgery residents are seeking cardiothoracic surgical training. During the last four years up to $55 \%$ of residency programs have gone unfilled and women continue to be underrepresented in our residency programs. This decreasing applicant pool portends a looming crisis, which has resulted from a combination of factors. With an increase in demand for cardiothoracic procedures due to an increasing and aging population, combined with a diminishing thoracic surgical workforce, the United States will soon be unable to provide adequate access for those needing cardiothoracic surgery. In addition to a shrinking thoracic surgical workforce, many residents are finishing programs lacking technology skills critical to the modern cardiothoracic surgeon, and some are not able to handle increasingly complex yet common clinical practice scenarios. This year alone $22 \%$ of residents failed the qualifying (oral) examination of the American Board of Thoracic Surgery. Combined, all of these issues could form a perfect storm for our specialty, if not addressed soon.

Over the last 10 years new technology for treating cardiovascular and thoracic diseases has advanced remarkably. The explosion of new, less invasive interventional and catheterbased techniques in cardiology, pulmonology, gastroenterology, radiology, and vascular surgery has eroded referrals for well-proven cardiothoracic operations. Moreover, there are many more career options for medical students wanting a procedure based specialty. In the past the length of surgical training and the intensity of a cardiothoracic surgical practice was compensated, both financially and in professional prestige, and therefore were less significant in decisions to enter the specialty. However, now work hours, lifestyle issues, length of training, and concerns over specialty viability all have

President (WRC), The Society of Thoracic Surgeons, Chicago, Illinois; President (TLS), The American Association for Thoracic Surgery, Beverly, Massachusetts; Chair (RHF), American Board of Thoracic Surgery, Chicago, Illinois; President (MJM), Thoracic Surgery Foundation for Research and Education, Beverly, Massachusetts.

This article is being published simultaneously in The Annals of Thoracic Surgery and The Journal of Thoracic and Cardiovascular Surgery.

Address for correspondence: W. Randolph Chitwood, Jr, MD, Department of Cardiovascular Science, East Carolina Heart Institute, East Carolina University, 600 Moye Blvd, Greenville, NC 27835 (E-mail: chitwoodw@ecu.edu).

J Thorac Cardiovasc Surg 2008;136:812-3

$0022-5223 / \$ 34.00$

Copyright (c) 2008 by The American Association for Thoracic Surgery and The Society of Thoracic Surgeons

doi:10.1016/j.jtcvs.2008.08.012 become major factors in selecting a career path. This evolution is no less concerning for practicing surgeons, who in short order must adopt new technology to supplement and advance their skills. Thus, our specialty has an acute "mission critical" mandate to reform and improve thoracic surgery resident and postgraduate education alike.

It is incumbent that we, the practicing thoracic surgeons, embrace actively this mandate and become enthusiastic about leading a renaissance in thoracic surgery education. In the United States, the American Association for Thoracic Surgery (AATS) and the Society of Thoracic Surgeons (STS), as well as the Southern and Western Thoracic Surgical Associations (STSA, WTSA) have been mainstays of postgraduate thoracic surgical education. Resident training and educational content have been guided by the Thoracic Surgery Directors Association (TSDA) with program evaluation and certification done by the Thoracic Surgery Residency Review Committee of the Accreditation Council for Graduate Medical Education (ACGME). The American Board of Thoracic Surgery (ABTS) has been responsible for primary certification as well as maintenance of certification for surgeons who have completed approved training programs. To recruit and provide research grant funds for residents and young academic surgeons, the Thoracic Surgery Foundation for Research and Education (TSFRE) was founded by the STS, AATS, STSA, and WTSA. In 1996 these organizations formed the Joint Council for Thoracic Surgery Education (JCTSE) to cross pollinate and coordinate thoracic surgery education. The JCTSE was an assembly of leaders from the aforementioned organizations, who aspired, "to bring together representatives of those organizations to which thoracic surgery education is critically important in order to continuously monitor the thoracic surgery education process and factors which influence it and pro-actively to recommend appropriate changes that are deemed necessary". This unincorporated confederation had no elected officers and was powerless to affect policy, governance, or collect and disperse funds for education. The term "no money, no power" was a great impediment to the JCTSE being able to change resident education. It did, however, establish filial communication channels between these organizations, who all aspired to coordinate and improve thoracic surgical education. Also, the JCTSE became a fitting template to organize new efforts and make thoracic surgical education more comprehensive and more uniform.

Over a year ago the leadership of each of our national cardiothoracic surgery organizations heard the clarion call to reform thoracic surgical education and responded loudly through two "Summits", which clarified the urgency, direction, and elements needed to make rapid course corrections. 
From these discussions, a solid consensus emanated that a robust, powerful, and effective organization must be organized immediately. To this end, the JCTSE was incorporated early this year, and a Board of Directors was selected from the leadership of the funding organizations (AATS, ABTS, STS and TSFRE). These organizations have pledged jointly up to one million dollars per year, for at least the next four years, for development and initiation of innovative new teaching methods. Within the JCTSE Inc. an advisory board, comprised of members from all of the organizations involved in cardiothoracic education, was selected and a search for a Surgical Director of Education is underway. Currently, the selection committee is interviewing excellent candidates for the Surgical Director position, and this individual should be in place before the first board meeting of the JCTSE Inc. in October. The TSDA was selected to be the vector organization to initiate these new models for resident education while a postgraduate education committee is slated to coordinate and redefine pathways for educating practicing surgeons. Recently, the TSDA sponsored a thoracic surgical skills "boot camp" for incoming thoracic residents. As you will see in the accompanying editorial by Dr George Hicks, it was a booming success and represents a giant step forward for thoracic surgical education. There is much to be done regarding simulation, specialty cross-training, new technology, and many other areas. This effort is also dedicated firmly to the acute need for post-residency training in these areas and view practicing surgeons as a most important part of these initiatives. Working together we can guide our specialty in the right direction and provide our patients with up-to-date innovative therapy while enlisting the best applicants to our programs.

In just over a year our commitment has come a long way but we are-just at the beginning! 